\title{
D-Dimer Improves the Prognostic Value of Combined Clinical and Laboratory Data in Equine Gastrointestinal Colic
}

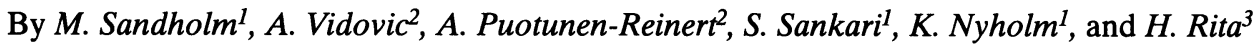 \\ ${ }^{1}$ Department of Clinical Sciences, College of Veterinary Medicine, Helsinki, Finland, ${ }^{2}$ Hochmoor Tierklinik, \\ Gescher-Hochmoor, Germany, and ${ }^{3}$ Department of Forest Resource Management/Statistics, University of Hel- \\ sinki.
}

\begin{abstract}
Sandholm, M., A. Vidovic, A. Puotunen-Reinert, S. Sankari, and K. Nyholm: D-Dimer improves the prognostic value of combined clinical and laboratory data in equine gastrointestinal colic. Acta vet. scand. 1995, 36, 255-272. - The discrımınatıng ability of 15 parameters alone or in combinations, including results from analysis of plasma endotoxin, the Nycomed plasma D-Dimer test and phospholipase $A_{2}$, were analyzed to predict morbidity and mortality in equine gastrointestinal colic. Endotoxaemia was a characteristic feature of the colic horses. The problem of adequately predicting nonsurvivors among colic horses required several parameters to be included in the logistic model: if the "classical parameters", (heart rate, respiratory rate, PCV, anıon gap) were included in the model, addition of plasma D-dimer, phospholipase $\mathrm{A}_{2}$, and $\mathrm{Cl}^{-}$significantly improved the predictive value of the logistic model. Increasing heart rate and Ddimer together with decreasing chloride was a risk factor for nonsurvival. The sensitivity of this three-parameter logistic model to predict nonsurvival was $78 \%$ and specificity $77 \%$. The Nycomed D-Dimer test is recommended as a horse-site test to predict disseminated intravascular coagulation and nonsurvival in equine colic.
\end{abstract}

horse; diagnosis; acute phase; mortality; inflammation; enzymes; sorbitol dehydrogenase; phospholipase; glutamate dehydrogenase; endotoxin; acid-base; thrombosis; fibrinolysis; DIC.

\section{Introduction}

Equine colic attributable to gastrointestinal tract disease is the leading cause of death in adult horses. Horses with acute abdominal crisis (colic) require immediate clinical decision-making as they often need surgery to open up mechanical obstructions, strangulations or displacements and to remove necrotic parts of the intestine. The operation requires skilful surgery, patient surveillance, and it is expensive. The mortality associated with such operations is high. Statistics from North
American university clinics have shown that $40 \%$ of colic horses die in spite of surgery (Morris 1991). Therefore, it is highly desirable to have predictive clinical and laboratory tests to identify cases that need urgent surgical intervention and to judge whether irreversible damage already exists to indicate a hopeless prognosis.

When the intestinal wall is damaged, intestinal microflora-derived endotoxin is found in blood. The clinical features of gastrointestinal colic are very much the same as in gram-neg- 
ative sepsis where the glycolipoid cell wall constituents (endotoxin, lipopolysaccharide, LPS) trigger the host to synthesize cytokines such as TNF $\alpha$, IL-1 and IL-6. Cytokines in turn may induce the systemic inflammation response syndrome (SIRS) of the host and clinical features. Sepsis patients generally do not die of infection but of a hyperbolic inflammatory and an immune response that involves numerous biological pathways. The disease culminates in fluid- and acid-base disturbance, diffuse coagulopathy, multiple organ dysfunctions, and finally death. Survival largely depends on the degree of cardiovascular and metabolic derangement resulting from the lesion and host response.

Several studies have analyzed the diagnostic and prognostic value of predictor parameters and parameter combinations measured in routine examination of colic patients (Parry et al. 1983, Puotunen-Reinert \& Sandholm 1985, Puotunen-Reinert 1986, Orsini et al. 1991, Reevers et al. 1992). High pulse rate associated with high packed cell volume, dull colour of mucous membranes, delayed oral mucous capillary refill time, disturbances in acid-base parameters (such as increased anion gap), and a hypercoagulative condition are currently considered valuable markers and can be used as predictors for poor prognosis in equine colic (Darien et al. 1991, Gossett et al. 1987, Johnston \& Crane 1986, Orsini et al. 1988 \& 1991, Wirth 1986). High blood lactate level has been taken as an estimator for the depth of shock (Gossett et al. 1987, Waterman 1977).

Our research objective was to develop a quantitative colic assessment method that would provide a reliable clinical tool to predict mortality before the horse undergoes surgery. Therefore, the applicability of the conventional markers (heart rate, breath rate, PCV, ionic composition of plasma, acid-base parameters) as well as plasma endotoxin, indica- tors of thrombotic and fibrinolytic activities and the enzymes phospolipase $\mathrm{A}_{2}\left(\mathrm{PLA}_{2}\right)$, sorbitol dehydrogenase (SDH) and glutamic dehydrogenase (GLDH) were compared. The study design was to collect a similar number (about 50) of surviving colic horses, nonsurviving colic horses and controls, and to analyze retrospectively, which physiological and laboratory analyses would be most valuable alone or in combinations to allocate the horses correctly.

\section{Materials and methods}

The material consisted of 105 horses with severe gastrointestinal colic, delivered for operation between March 1992 and November 1992 to the Hochmoor Animal Hospital, Gescher-Hochmoor, Germany. Eighty patients were operated and 25 were treated conservatively; 42 colic horses died or had to be euthanized within 3 days. Another 52 healthy horses served as controls. Table 1 summarizes the classification of the patients.

After the clinical examination, venous and arterial blood samples were drawn for acid-base studies and laboratory analyses. Blood samples were collected again at $10 \mathrm{~h}$ intervals irrespective of the stage of surgery. The total number of blood samples from colic horses was 229.

Table 1. Classification of horses included in the study.

\begin{tabular}{lr}
\hline Diagnosis & No \\
\hline Colic attributable to gastrointestinal disease & 105 \\
Involvement of small intestıne & 41 \\
Involvement of large intestine & 51 \\
Combined problem (small \& large intestıne) & 5 \\
Ruptured intestıne & 4 \\
Peritonitıs & 2 \\
Other gastrointestinal problems & 2 \\
Healthy control horses & 52 \\
\hline
\end{tabular}




\section{Laboratory analyses}

Packed cell volume (PCV) was analyzed by the capillary microcentrifuge method using heparinized blood samples.

Acid-base parameters, $\mathrm{pH}, \mathrm{pO}_{2}, \mathrm{pCO}_{2}$, bicarbonate and base excess were studied from arterial blood samples using the $\mathrm{ABL}$ 300 Acid-Base Laboratory (Radiometer, Copenhagen, Denmark).

Serum electrolytes. Sodium, potassium and chloride were analyzed using ion-selective electrodes (Microlyte $3+2$ Ion-selective Analyzer, Kone Oy Espoo, Finland). The anionic gap was calculated of the difference $\left(\mathrm{Na}^{+}+\mathrm{K}^{+}\right)-\left(\mathrm{HCO}_{3}^{-}+\mathrm{Cl}^{-}\right)$.

Endotoxin concentration in blood plasma. The analysis was carried out by the Limulus amoebocyte lysate test (LAL) using the chromogenic COATEST ${ }^{\circledR}$ kit (Chromogenix AB, S-431 53 Mölndahl, Sweden) as the endpoint assay. The measurements were carried out at $37^{\circ} \mathrm{C}$ using the Labsystems FP-901 analysing system (Labsystems, Pulttitie 8, P.O.B. 8, 00881 Helsinki, Finland). The heparinized venous blood samples were diluted 1:10 with pyrogen-free distilled water and heat-treated in a water bath at $75^{\circ} \mathrm{C}$ for $5 \mathrm{~min}$. The pretreated plasma samples were mixed with an equal volume $(50 \mu \mathrm{l})$ of LAL reagent and standards and incubated for $30 \mathrm{~min} ; 100$ $\mu l$ of the chromogenic protease substrate was added and incubated further for $10 \mathrm{~min}$. The substrate conversion was stopped by adding $100 \mu \mathrm{l}$ of $20 \%$ acetic acid and the released para-nitroaniline was measured photometrically at $405 \mathrm{~nm}$. Plasma blanks were used throughout the procedure because plasma samples from colic horses were often haemolytic or lipemic. Least-square linear fitting was used to produce the regression line to be used for interpolation of the endotoxin contents.

Fibrinogen concentration of plasma. Venous blood was drawn in citrated Vac- utainer $^{\circledR}$ tubes (Becton Dickinson No 12697 , North Canaan, CT / Broken Bow, NE, U.S.A). Plasma was separated by centrifugation, $3000 \mathrm{~g} / 10 \mathrm{~min}$. The plasma was transferred in siliconized glass tubes and stored at $-20^{\circ} \mathrm{C}$ until analyzed. The plasma samples were diluted $1: 8$ with barbital buffer, $0.02 \mathrm{M}$, $\mathrm{pH}$ 8.6. An equal volume of thrombin ( $300 \mu \mathrm{l}$ containing 9 N.I.H units thrombin (Topostasine ${ }^{\circledR}$, Roche, F. Hoffmann-La Roche \& Co. AG, Basel, Switzerland) in the barbital buffer was mixed at $37^{\circ} \mathrm{C}$ with diluted plasma samples in 9-well microcuvettes. The Labsystems FP-901 Chemistry Analyzer was used. The increase in turbidity, as measured between 2 and $60 \mathrm{sec}$, showed linear relationship with the fibrinogen contents. Fibrinogen standards were prepared from plasma from a control horse with known fibrinogen level (which had been analyzed with the fibrin clot protein method) by diluting it $1: 8,1: 16$ and $1: 32$ in $0.9 \%$ saline.

Plasma D-dimer. The fibrin(ogen) degradation product $\mathrm{D}$-dimer was analyzed by the Nycomed NycoCard D-Dimer test (Nycomed Pharma Oslo, Norway). The test is based on immunofiltration through a membrane with attached monoclonal antibody and secondary staining with colloidal gold-labelled monoclonal antibody (Fig. 1) (Gogstad et al. 1993). In pilot studies we observed a cross reactivity between human and equine D-dimer using the test antibody.

Sorbitol dehydrogenase (SDH, EC 1.1.1.14) activity of plasma was analyzed by the method of Gerlach \& Hiby (1974).

Glutamate dehydrogenase (GLDH, EC 1.4.1.3) activity of plasma was analyzed according to the recommendations of the German Society for Clinical Chemistry.

Phospholipase $\mathrm{A}_{2}$ (PLA, EC 3.1.1.4) activity of plasma was analyzed by radial enzyme diffusion in lecithin-agar gels essentially 


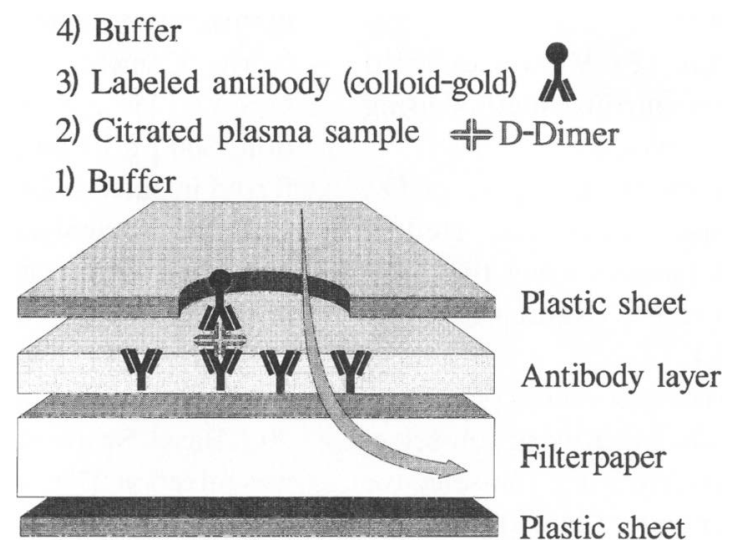

Figure 1. Principle of the NycoCard D-Dimer test. A filter paper layer is used to suck the plasma sample (50 $\mu \mathrm{l})$ through the membrane with fixed antibody (both antibodies against D-Dimer). The trapped D-dimer is detected by the colloid-gold labelled second antibody. A purple colour (colloid-gold) indicates presence of DDimer in the plasma sample. The intensity of the colour is measured from the top by a reflectance meter or interpolated visually using a colour scale as reference. The result is obtained within 2 min. Elevated D-dimer indicates ongoing thrombosis and fibrinolytic process (disseminated intravascular coagulation DIC).

as described by Puotunen-Reinert \& Sandholm (1985), but replacing the soybean lecithin with egg yolk. Thereby, the sensitivity of the assay increased. The turbid $2 \mathrm{~mm}$ thick agar plate contained $0.11 \%$ micellar egg yolk and 1\% agar in $0.125 \mathrm{M}$ TRIS-buffer, $\mathrm{pH} 8.0$ containing $4 \mathrm{mM} \mathrm{CaCl}$, and $0.1 \% \mathrm{NaN}_{3}$ as preservative. The $4 \mathrm{~mm}$ diameter wells were filled with $20 \mu \mathrm{l}$ of plasma samples. The diameters of the cleared zones were measured after $24 \mathrm{~h}$ of diffusion at $37^{\circ} \mathrm{C}$. For interpolation, a standard dilution series of phospholipase $\mathrm{A}_{2}$ (2, 0.2 and $0.02 \mathrm{U} / \mathrm{ml}$, Sigma P-6534, Sigma Chemical Company St. Louis, MO, U.S.A.) was run in parallel. The interpolation was carried out using a log-linear least-squares fitting ( $\log$ of PLA activity versus diameter of the cleared zone).

\section{Statistical analysis}

Two major problems in equine colic are A) which parameters and combinations separate healthy and colic horses, and B) which parameters or combinations predict nonsurvival within the colic horses. The dynamic nature of the condition has to be considered, so we also looked at changes which occurred within the first $10 \mathrm{~h}$ at the clinic.

Univariate analysis. As the distributions of several parameters did not appear normal, Spearman's rank-order correlation matrices (Tables 3 and 4) were used for exploratory data analysis. Transformations (In transformation or squaring) were used to normalize the distribution of each parameter. When calculating diagnostic sensitivity and specificity, the threshold value of each parameter was set manually at the point where the vertical distance of the sigmoidal cumulative distribution of each pair (Fig. 2) was at its widest (maximum number of correct answers when the number of samples in both groups is identi- 
Table 2. A. Comparıson of samples from colıc horses and control horses collected at admission. B. Comparsson of survivors and nonsurvivors within the colic horses. Means, medians and significance of differences are given. The significance of the difference is based on nonparametric comparison (Mann-Whitney U-test).

\begin{tabular}{|c|c|c|c|c|c|c|c|c|c|c|}
\hline \multirow[b]{3}{*}{ Parameter } & \multicolumn{4}{|c|}{ A. } & \multirow[b]{3}{*}{ (p) } & \multicolumn{4}{|c|}{ B. } & \multirow[b]{3}{*}{ (p) } \\
\hline & \multicolumn{2}{|c|}{$\begin{array}{l}\text { Controls } \\
(\mathrm{n}=52)\end{array}$} & \multicolumn{2}{|c|}{$\begin{array}{c}\text { Colic } \\
(n=105)\end{array}$} & & \multicolumn{2}{|c|}{$\begin{array}{l}\text { Colıc survivors } \\
\quad(n=63)\end{array}$} & \multicolumn{2}{|c|}{$\begin{array}{l}\text { Colic nonsurvivors } \\
\quad(n=42)\end{array}$} & \\
\hline & Mean & Median & Mean & Median & & Mean & Median & Mean & Medıan & \\
\hline Heart rate/min & 44.5 & 44.0 & 70.7 & 70.0 & 0.000 & 65.5 & 60.0 & 79.1 & 80.0 & 0.000 \\
\hline Breath rate/min & 12.7 & 12.0 & 28.9 & 24.0 & 0.000 & 27.9 & 24.0 & 30.7 & 28.0 & 0.173 \\
\hline PCV \% & 39.0 & 39.0 & 46.4 & 45.0 & 0.000 & 44.1 & 43.0 & 49.8 & 49.5 & 0.005 \\
\hline $\mathrm{K}^{+} \mathrm{mEq} / \mathrm{l}$ & 4.3 & 4.3 & 3.4 & 3.4 & 0.000 & 3.4 & 3.3 & 3.5 & 3.5 & 0.730 \\
\hline $\mathrm{Na}^{+} \mathrm{mEq} / \mathrm{l}$ & 138.5 & 139.0 & 139.3 & 139.0 & 0.084 & 139.6 & 139.0 & 138.9 & 139.5 & 0.529 \\
\hline $\mathrm{Cl}^{-} \mathrm{mEq} / \mathrm{l}$ & 100.9 & 101.0 & 98.3 & 99.0 & 0.000 & 99.2 & 99.0 & 96.9 & 97.5 & 0.013 \\
\hline $\mathrm{HCO}_{3}^{-} \mathrm{mEq} / \mathrm{l}$ & 27.5 & 28.0 & 26.5 & 26.4 & 0.134 & 27.0 & 26.9 & 25.7 & 26.0 & 0.124 \\
\hline Anion gap mEq/l & 14.4 & 14.3 & 18.0 & 16.9 & 0.000 & 16.7 & 16.6 & 19.8 & 18.5 & 0.007 \\
\hline Endotoxın ng/l & 5.9 & 5.1 & 66.0 & 76.0 & 0.000 & 66.7 & 79.3 & 64.7 & 65.8 & 0.917 \\
\hline Tot.plasma prot. g/l & 63.2 & 62.0 & 67.7 & 67.0 & 0.009 & 67.3 & 66.0 & 68.5 & 70.0 & 0.473 \\
\hline Fibronogen g/l & 4.0 & 3.8 & 3.5 & 3.3 & 0.000 & 3.3 & 3.3 & 3.7 & 3.1 & 0.631 \\
\hline D-dimer $\mathrm{mg} / \mathrm{l}$ & 0.2 & 0.2 & 0.8 & 0.5 & 0.000 & 0.5 & 0.5 & 1.2 & 0.6 & 0.004 \\
\hline Phospholipase U/ml & 297.0 & 265.1 & 507.5 & 370.8 & 0.000 & 394.5 & 313.5 & 677.1 & 457.4 & 0.005 \\
\hline SDH U/l & 3.2 & 2.3 & 9.8 & 4.7 & 0.000 & 8.3 & 3.7 & 12.0 & 6.5 & 0.000 \\
\hline GLDH U/1 & 2.2 & 1.1 & 36.4 & 3.4 & 0.000 & 28.5 & 2.2 & 48.5 & 4.3 & 0.033 \\
\hline
\end{tabular}

cal). The same variable sets were analyzed by logistic regression. In this case, the threshold was placed at 0.5 probability level; $\pi(\mathrm{p})=1 / 2$. The aim was to use an objective threshold criterion and to avoid specific features of this data to influence the estimation discriminating potential (diagnostic specificity and sensitivity) of each predictor. The sensitivity ("true positives") and specificity ("true negatives") percentages derived from comparison of observed and predicted probabilities (Table 5). In colic horses for which there was more than 1 sample (the second sampling at $10 \mathrm{~h}$ from admission), the $10 \mathrm{~h}$ value and the $0-10 \mathrm{~h}$ change of each parameter were used as additional predictors. This would indicate the trend showing which parameters become more important towards death. The Statgraphics 6 plus statistical graphics package was used (Manugistics, Rockville, MD, U.S.A.). The Statistix 4.1 package was used for logistic pro- cedures (Analytical Software, Tallahassee, FL, U.S.A.)

Multivariate statistics. Multiple logistic regression, was used as the means for selecting predictor variables to differentiate $\mathrm{A}$ ) between healthy and colic, and B) between survivors and nonsurvivors. We first studied whether the "new" variables (endotoxin, Ddimer, PLA, SDH, GLDH and $\mathrm{Cl}^{-}$) would improve the model when added to the "classical" set of predictors (heart rate, breath rate, PCV and anion gap). The "new" variables were added one by one to the model including the "classical" variables. The observed proportion of deaths (or disease, in problem A) was compared with the expected proportion (i.e. predicted by logistic regression models) for each increment. Their significance was based on the improvement of $\mathrm{G}^{2}$ statistic. The other method was to avoid assumptions and to find out which set of parameters would re- 
Table 3. Spearman's rank correlation matrix including admission data and the diagnostic category (control = 0 ), (gastrointestinal colic $=1)$. The significance $(p)$ is given below each pairwise correlation estimate.

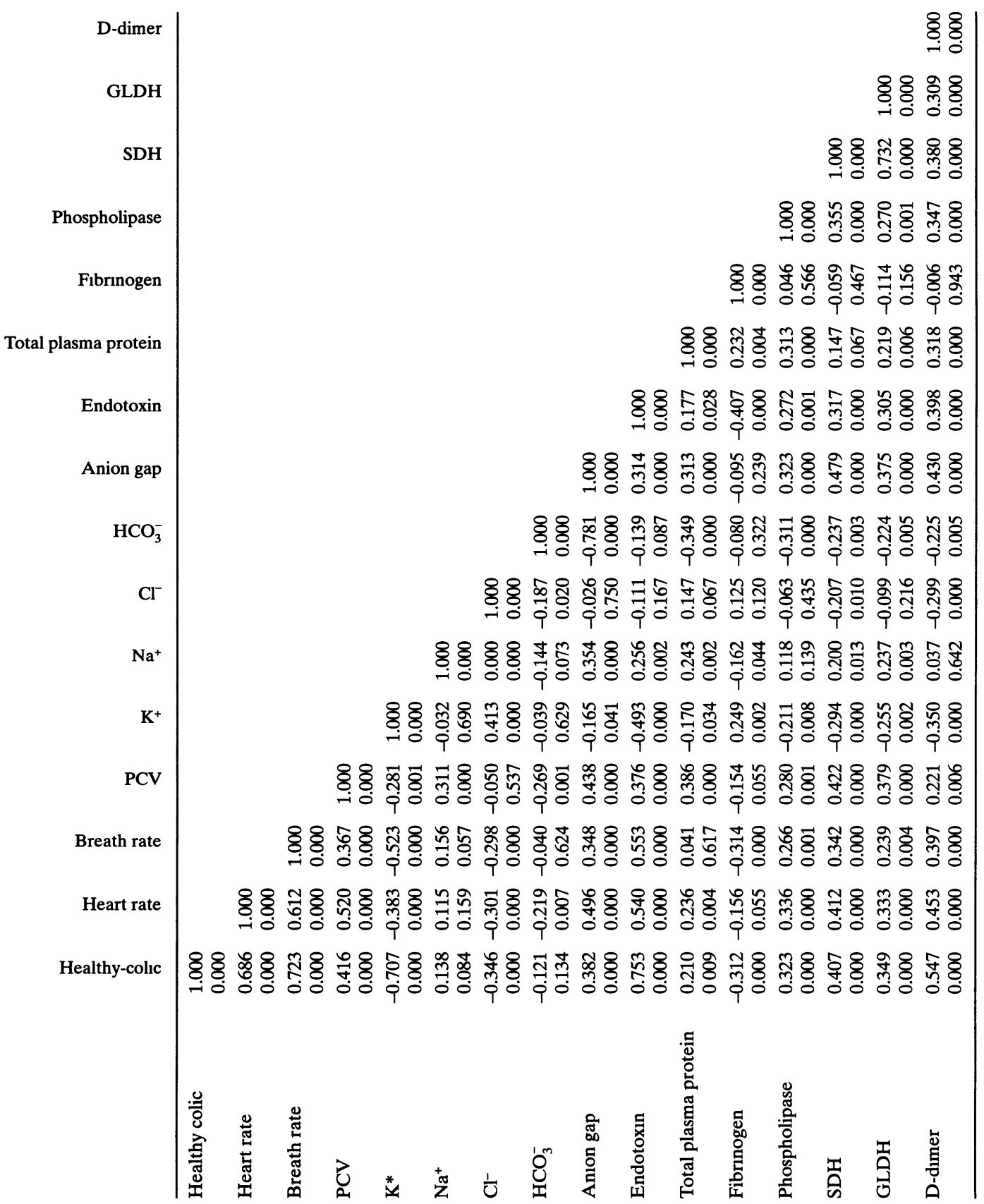


Table 4. Spearman's rank correlation matrix on colic horses including admission data and the fate of the horse (survivors $=0$ ), (nonsurvivors $=1$ ). The significance $(p)$ is given below each pairwise correlation estimate.

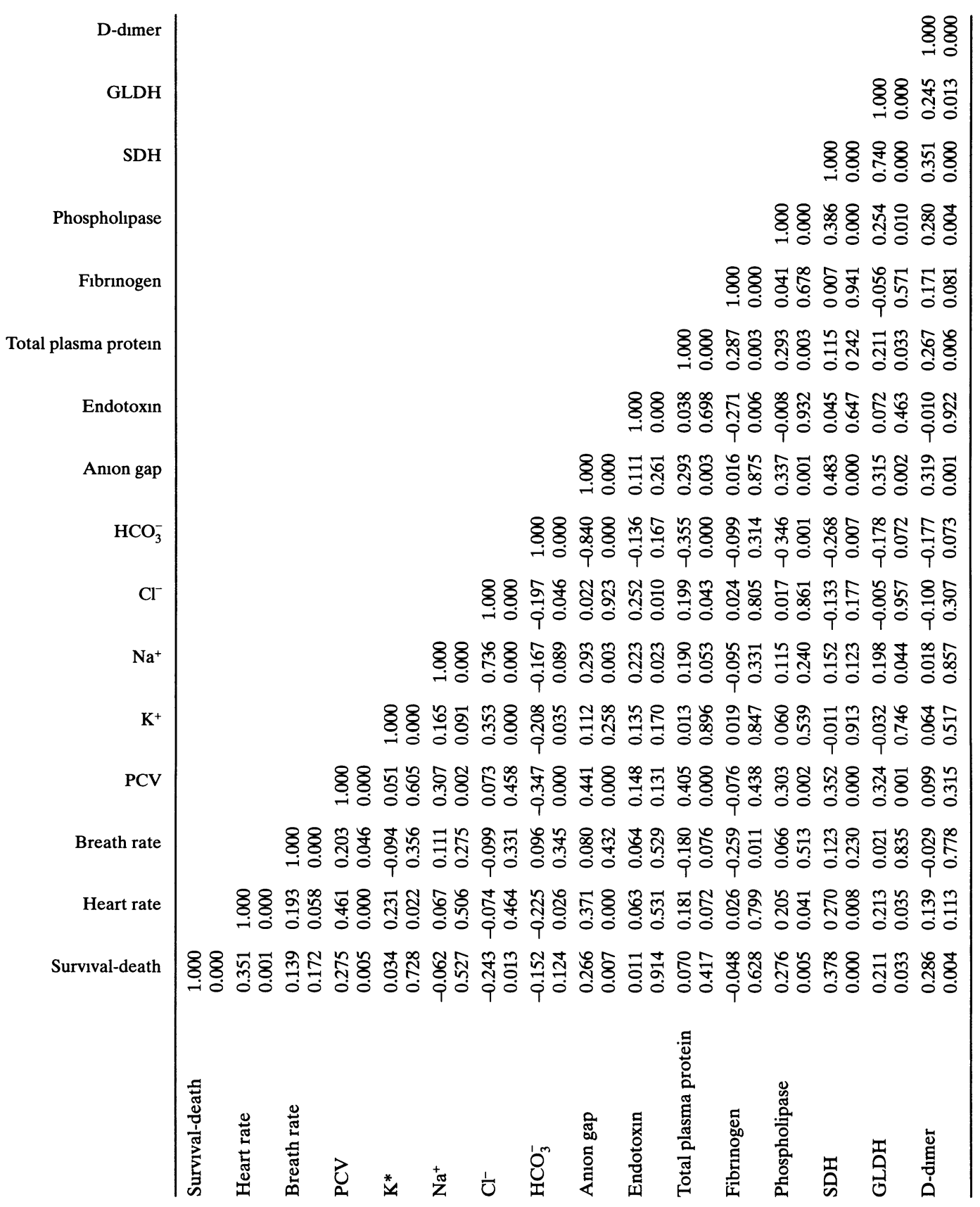



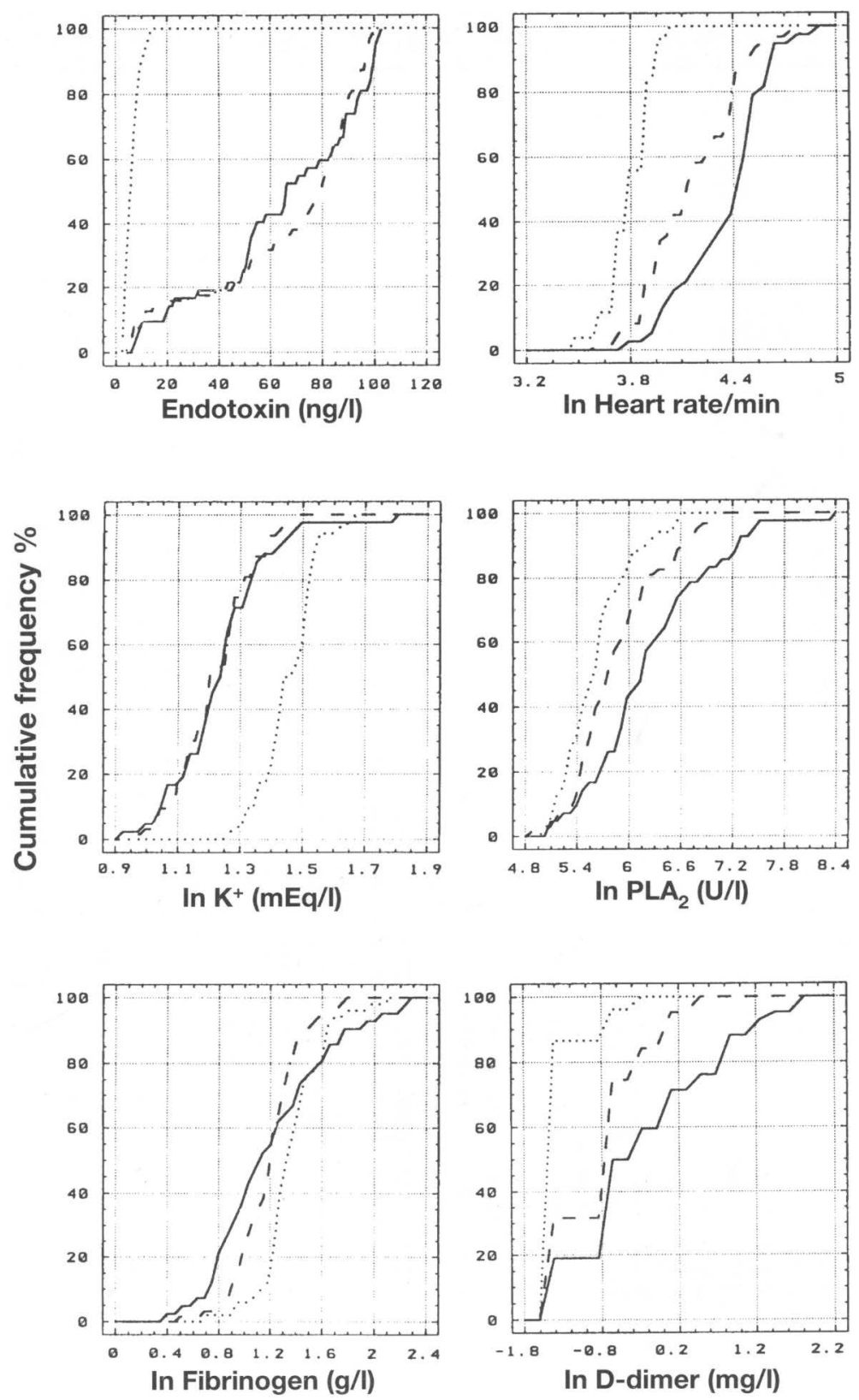

Figure 2. Cumulative frequency distribution graphs on selected parameters at admission. The nonsurvivors among the colic horses are indicated by solid line (_), the survivors by dashed line (--) and the healthy controls by dotted line (...). 
Table 5. Diagnostic sensitivity and specificity of individual parameters and acceptable combinations to predict intestınal colic (A) or nonsurvival (B). The specificity and sensitıvity values derive from observed frequencies by placing the threshold at a level where the $\%$ of correct predictions was at its maximum (when the number of samples in both groups are the same). The values in parenthesis are predictions from logistic regression where the decision threshold was set at the 0.5 probability level.

\begin{tabular}{|c|c|c|c|c|}
\hline \multirow[b]{2}{*}{ Parameter } & \multicolumn{2}{|c|}{$\begin{array}{c}\text { A } \\
\text { Health or disease? }\end{array}$} & \multicolumn{2}{|c|}{$\begin{array}{c}\text { B } \\
\text { Survival or nonsurvival? }\end{array}$} \\
\hline & Sensitivity & Specificity & Sensitivity** & Specificity** \\
\hline Heart rate/min & $74(90)$ & $96(73)$ & $74(70)$ & $58(71)$ \\
\hline Breath rate/min & $80(84)$ & $94(83)$ & $73(50)$ & $43(64)$ \\
\hline PCV \% & $57(71)$ & $90(56)$ & $53(69)$ & $85(70)$ \\
\hline $\mathrm{K}^{+} \mathrm{mEq} / 1$ & $86(89)$ & $91(82)$ & NA* & $\mathrm{NA}^{*}$ \\
\hline $\mathrm{Na}^{+} \mathrm{mEq} / \mathrm{l}$ & $17,31^{\#}(\S)$ & $95,92^{\#}(\S)$ & NA* & NA* \\
\hline $\mathrm{Cl}^{-} \mathrm{mEq} / \mathrm{l}$ & $62(66)$ & $79(21)$ & $50(53)$ & $71(63)$ \\
\hline $\mathrm{HCO}_{3}^{-} \mathrm{mEq} / \mathrm{l}$ & $36,25^{\#}(\S)$ & $95,92^{\#}(\S)$ & $78(*)$ & $59\left(^{*}\right)$ \\
\hline Anıon gap $\mathrm{mEq} / \mathrm{l}$ & $76(68)$ & $65(41)$ & $41(68)$ & $87(68)$ \\
\hline Endotoxin ng/l & $88(97)$ & $100(78)$ & $52(*)$ & $54(*)$ \\
\hline Tot. plasma prot. $\mathrm{g} / \mathrm{l}$ & $10,47^{\#}(\S)$ & $100,84^{\#}(\S)$ & $65(*)$ & $49(*)$ \\
\hline Fibrinogen g/l & $60(67)$ & $79(33)$ & $28,29^{\#}(\S)$ & $93,90^{\#}(\S)$ \\
\hline D-dımer mg/l & $73(92)$ & $87(62)$ & $50(80)$ & $75(67)$ \\
\hline $\mathrm{PLA}_{2} \mathrm{U} / \mathrm{ml}$ & $66(69)$ & $67(53)$ & $72(60)$ & $57(65)$ \\
\hline SDH U/l & $68(69)$ & $76(70)$ & $54(50)$ & $73(61)$ \\
\hline GLDH U/l & $75(*)$ & $62(*)$ & $74(67)$ & $47(62)$ \\
\hline Combination & (100) & $(100)$ & (78) & (77) \\
\hline (logistic model) & \multicolumn{2}{|c|}{ (endotoxın, $\mathrm{K}^{+}$, heart rate, $\mathrm{D}$-dimer) } & \multicolumn{2}{|c|}{ (D-dımer, $\mathrm{Cl}^{-}$, heart rate) } \\
\hline
\end{tabular}

** Diagnostic sensitıvity to predict nonsurvival is the percentage of nonsurviving horses which were designated as nonsurvivors by the diagnostic test. The specificity is the percentage of surviving horses which were designated as survivors by the same threshold setting.

* NA "not applicable": The distributıons were closely identical The $p=0.5$ threshold setting did not distinguish between the groups.

\# Two optımal threshold settıngs were found.

$\S$ Due to nonmonotonic behaviour, the logistic model was not applicable.

sult in a simple combination in terms of acceptable sensitivity and specificity. In the latter approach, all the 15 predictors were included in the model and backward elimination was used as the means to eliminate less important and collinear predictors.

\section{Results}

Of the 105 colic horses, 63 survived but 42 failed to survive the intestinal colic episode. The mortality was $44 \%$ among the operated horses and $28 \%$ among the conservatively treated horses. The analysis of the 15 variables to classify the groups (52 controls, 63 survivors and 42 nonsurvivors) correctly gave the following results.

\section{Single parameters}

The measured values of blood samples collected at admission to the clinic are summarized in Table 2. Most of the parameters except plasma $\mathrm{HCO}_{3}^{-}$and $\mathrm{Na}^{+}$showed significant differences between the colic and control horses. The correlation matrixes (Spearman's rank 

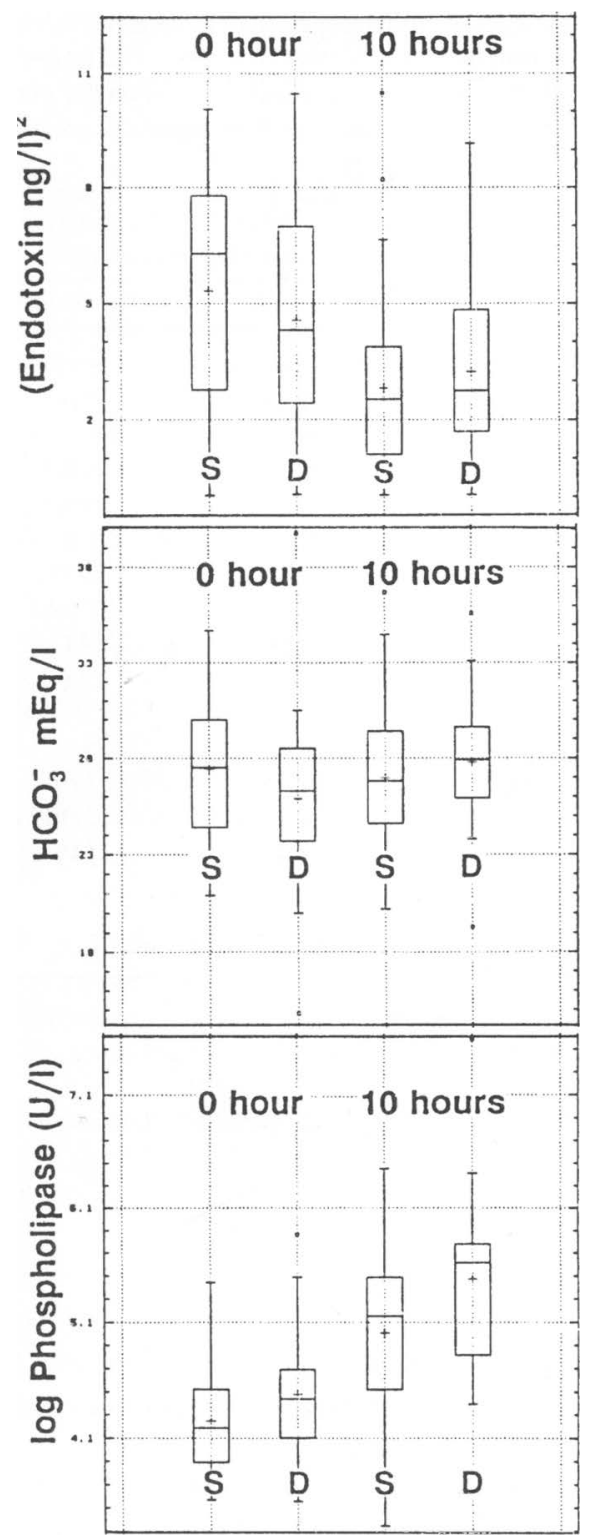

Fig.3. Box-and-Whisker plots on plasma endotoxin, bicarbonate and phospholipase-A2 levels at admission ( 0 hour) and $10 \mathrm{~h}$ later in colic horses going to survive (S), $n=42$, or die (D), $n=25$. The increase in bicarbonate between 0 and $10 \mathrm{~h}$ was significantly higher in nonsurvivors compared with the survivors $(\mathrm{p}=0.003)$. correlations) including the binary correlation with the health $(0)$ or disease $(1=$ gastrointestinal colic) are presented in Table 3 . The correlation matrix on admission data from colic horses, including the binary correlation with the future of the horse (survivors $=0$, nonsurvivors $=1$ ), is presented in Table 4 .

The results of the admission levels of plasma endotoxin, heart rate, plasma potassium, $\mathrm{PLA}_{2}$, fibrinogen and D-dimer distinguishing between healthy and colic horses as well as survival and nonsurvival are given as cumulative frequency distribution graphs in Fig. 2.

Compared with survivors, horses that failed to survive the intestinal colic episode had significantly different median admission levels of plasma SDH, heart rate, D-dimer, $\mathrm{PLA}_{2}$, $\mathrm{PCV}$, anion gap, $\mathrm{Cl}^{-}$, and $\mathrm{GLDH}$, listed in the order of statistical significance (Table 2). The binary correlation of each parameter with survival (0) - death (1) were similar (Table 4). The plasma samples of control horses were visually clear. However, $12.7 \%$ of the plasma samples from colic horses $(n=229)$ appeared lipaemic (turbidity, visual evaluation). Of the 29 lipaemic samples of colic horses, 22 originated from nonsurvivors.

Table 5 reports the diagnostic sensitivity and specificity of individual admission parameters A) to place healthy and colic horses in the correct groups, and B) to predict death or survival within the colic group. Endotoxin was the best discriminator between healthy and colic horses; the optimum threshold setting was 13 ng/l (Fig. 2). No diagnostically distinguishing features were found in the comparison of the site of intestinal disorder (small vs large intestinal impaction or obstruction).

The examination of single variables of colic horses in relation to the time after admission showed that the prediction of nonsurvival clearly improved with $\mathrm{K}^{+}$when moving from samples taken at admission to samples col- 
Table 6. Diagnostic sensitivity (correct classification \% of nonsurvivors) and specificity (correct classification $\%$ of survivors) of multiple logistıc regression models to predict nonsurvival among colıc horses: I) "classical" parameters, II) "classical" parameters with the model-improving new parameters and III) a simple and good theory-independent combination.

$\left.\begin{array}{ll|cc}\hline & \text { Combination } & \text { Sensitvity } & \text { Specificty } \\ \hline \text { I) Classical } & \begin{array}{l}\text { Heart rate } \\ \text { Breath rate } \\ \text { PCV } \\ \text { Anion gap }\end{array} \\ \text { II) Classical + New } & \begin{array}{l}\text { D-Dimer } \\ \text { PLA } \\ \text { Cl }^{-}\end{array} \\ \text {D-Dimer } \\ \text { D- } \\ \text { HII) A simple } \\ \begin{array}{l}\text { and good } \\ \text { combination }\end{array}\end{array}\right\}$

lected 10 hours later. Plasma potassium was generally low in colic horses in samples collected at admission (Table 2, Fig. 2) and decreased further for the first 10 hours. The discriminatory ability of GLDH increased slightly from 0 hour samples to 10 hour samples. $\mathrm{PLA}_{2}$ retained its discriminatory ability from 0 hour to 10 hour samplings. Therapy complicated the picture of all the other parameters; the 10 hour samples were inferior to the admission samples in discriminating between death and survival. The significance of anion gap as a predictor for death or survival lost its discriminating capacity completely during the first 10 hours at the clinic. The colic horses that subsequently died showed a significantly higher relative increase in bicarbonate (Fig. 3, $p=0.003$ ) and a decrease in anion gap ( $p=0.018)$ during the first 10 hours at the clinic, compared with the survivors. The change in plasma sodium correlated positively with the change of bicarbonate in the horses that did not survive $(p=0.07)$. GLDH was the only single enzymatic parameter that increased its discriminatory ability in the predic- tion of nonsurvival when $0-10$ hour differences were used, rather than absolute values. Plasma endotoxin levels generally decreased but plasma D-dimer and phospholipase increased in colic horses during the first 10 hours at the clinic but these changes were not related to survival (Fig. 3).

\section{Combined data (Logistic regression)}

A) Health or disease? When the physiological variables and laboratory values on blood samples collected from healthy and colic horses at admission were included in the model to place healthy and colic horses into correct groups, the most important predictor variables were endotoxin, potassium, heart rate, and D-dimer. The diagnostic sensitivity and specificity of the discrimination analysis based on the above model was $100 \%$ (Table 5). Endotoxin was a good predictor alone (Fig. 2, Table 5).

B) Survival or nonsurvival? Only colic horses were included. When admission samples from colic horses were analyzed to predict survival or nonsurvival and the "classical" pa- 
rameters (heart rate, breath rate, $\mathrm{PCV}$, anion gap) were included, only the pulse rate was statistically significant (Wald-test, p-value 0.027).

Addition of all the "new" variables together (endotoxin, fibrinogen, D-dimer, $\mathrm{PLA}_{2}, \mathrm{SDH}$, GLDH and $\mathrm{Cl}^{-}$) to the model containing the "classical" parameters significantly improved the model fit. The improvement $\mathrm{G}^{2}$ was 17.43 on 5 degrees of freedom, $p<0.001$. In this model, according to the Wald tests, only Ddimer and $\mathrm{Cl}^{-}$could be regarded as statistically significant $(\mathrm{p}=0.068$ and 0.057 ). The model suffered from inclusion of too many predictors; if the "classical" and "new" parameters were included together $(n=11)$ in the model, even heart rate was not significant $(\mathrm{p}=0.135)$.

When the effect of the "new" variables were added one by one to the model including the classical variables, the most significant ones were (based on the improvement $G^{2}$ ), Ddimer $(\mathrm{p}=0.001), \mathrm{PLA}_{2}(\mathrm{p}=0.022)$ and $\mathrm{Cl}^{-}(\mathrm{p}$ $=0.022)$. With these 3 variables added to the model the sensitivity and specificity of the prediction of nonsurvival were $70 \%$ and $73 \%$ (Table 6).

If the prediction model was constructed independent of assumptions of any parameters to be included, a simple and good combination of predictors included pulse rate, D-dimer and $\mathrm{Cl}^{-}$. The sensitivity of the model (to predict nonsurvival) was $78 \%$ and specificity $77 \%$. (Table 6). The logit model was:

$$
\begin{gathered}
\operatorname{logit}(\pi)=5.73204+0.03514 \text { heart rate }- \\
0.09788 \text { chloride }+1.16992 \text { D-dimer }
\end{gathered}
$$

( $\pi=$ probability of nonsurvival). Therefore, the risk for nonsurvival increased with pulse rate and D-dimer and decreased with $\mathrm{Cl}^{-}$. If the value of the right hand side of the above equation is positive, the horse is considered a nonsurvivor.

\section{Discussion}

This study was designed to select, from among a set of physiological and biochemical variables, those prognostically useful in equine gastrointestinal colic, independent of the extent and the nature of the lesion. We were especially interested to see whether a combination of parameters would be superior to any individual parameters and how to combine the parameters in the best possible way. Multivariate statistical methods have both descriptive and predictive functions. The process of intestinal colic is dynamic and currently there is no safe indicator to tell the point at which the horse is "over the edge" and cannot be saved. It is clear that the prognostic value of a parameter is dependent on the time at which it is sampled in relation to the ongoing process. There is no way to standardize the sampling in relation to the process; the prognostic value of each parameter changes with time. Therefore, the discriminatory ability (death or survival) of samples collected at 2 time points after admission were examined for differences as time elapsed. The colic horses were sampled at $10 \mathrm{~h}$ intervals, but as the number of nonsurviving colic horses decreased rapidly, we were not left with a sufficient sample for adequate statistical analysis beyond $10 \mathrm{~h}$. Whether the $0-10 \mathrm{~h}$ changes reflected specific effects of colic, acute-phase response or therapy, was not determined. The therapy and quality of the surgery certainly complicates the evaluation of the changes.

The quality of the information provided by a clinical or biochemical quantity in the diagnosis of a disease is dependent on its capacity to discriminate whether the disease exists or whether the animal is going to die. The results of the most important variables, distinguishing both between healthy and colic horses, and between survival and nonsurvival among the colic horses, are given as cumulative fre- 
quency percentage graphs (Fig. 2). This allows discrimination thresholds to be set at optimum levels when individual parameters are used. The smaller the overlapping area, the greater the diagnostic accuracy. The threshold setting can be adjusted according to the wanted diagnostic sensitivity and specificity. The predictive value can then be calculated according to these if the prevalence of the disease is known. Our study was designed to include about the same number of horses in each diagnostic category. This principle of including a similar number of horses in each category resulted in an apparent lower recovery figure than commonly experienced at the Hochmoor Animal Clinic.

Many parameters were quite effective in distinguishing between healthy and colic horses. The present investigation confirms the importance of heart rate, respiratory rate and PCV to be included in the clinical examination of the colic horse. However, these parameters were highly correlated (collinearity in regression models). Therefore the combination did not bring much additional information to the heart rate alone.

Plasma samples from colic horses were in several cases "milky" or haemolytic. Turbidity of plasma seems to be a marker of disease and poor prognosis. Because the evaluation was subjective, we did not include this information in the prediction model. The lipidaemic turbidity of plasma might indicate disturbance in lipid metabolism and ongoing membrane disrupting process. Plasma turbidity is known to increase in horses upon fasting. Due to the hyperlipidemic response to endotoxin, experimental animals might tolerate more endotoxin. Endotoxin-induced hyperlipoproteinemia might be a physiological defence mechanism whereby the body attempts to bind circulating endotoxin (Wei \& Floren 1993).

Plasma endotoxin was an extremely safe pa- rameter for identifying colic horses among healthy horses (Fig. 2, Table 5). This indicates that leakage of endotoxin from the gut into the blood is typical for gastrointestinal colic. Additional strength in the confirmation of the existence of the disease was gained by combining plasma $\mathrm{K}^{+}$, heart rate and $\mathrm{D}$-dimer with endotoxin in the regression model; by this logistic model all the horses became placed in their correct categories (healthy or colic).

Whenever the integrity of the mucosal barrier is lost due to inflammation or ischemia of the intestinal wall, endotoxins cross into the portal blood and peritoneal cavity and can be detected in the peripheral circulation. LPS has been detected in blood plasma of horses with gastrointestinal diseases that cause colic (King \& Gerring 1988). Theoretically, the amount of endotoxin in the blood should reflect the extent of damage to the intestinal wall. However, the plasma endotoxin level proved to have no prognostic value whatsoever in differentiating between survivors and nonsurvivors (Fig. 2, Table 5).

Much of the pathophysiology of intestinal colic can be explained by the adverse effects of endotoxemia. Actually, many endotoxin effects are mediated by endogenous factors derived from endotoxin-responding host cells. Various cytokines (such as TNF $\alpha$, IL-1 and IL-6) and other mediators that are produced by responding host cells cause aberrations in temperature regulation, haemodynamic-, haematologic-, and liver responses including regulation of the production of acute-phase proteins as well as regulation of the immunologic system (Morris 1991). Administration of IL-1 or TNF $\alpha$ to animals has been shown to induce many effects observed in Gram-negative and endotoxin-induced sepsis. When causing excessive response, LPS can cause irreversible multiple organ dysfunction known 
as the systemic inflammatory response syndrome (SIRS). Our results indicate that the limiting factor that determines the outcome of the endotoxin response (shock) is probably the susceptibility of the host to endotoxin rather than the plasma endotoxin level. This might be determined by up- and downregulation of the complex cytokine network.

Inflammation is accompanied by the acutephase response that comprises a constellation of metabolic, endocrinologic and immunologic alterations which start within hours of an initiating stimulus. Synthesis of acute-phase plasma proteins (APP:s) by the liver is a major component of acute-phase response. Therefore plasma fibrinogen and PLA $\mathrm{P}_{2}$ can be expected to increase in any inflammatory disease. Measurement of cytokines responsible for the endotoxin effects (eg TNF $\alpha$ or IL-6) may be a diagnostic aid during the first hours of an inflammatory state if the blood APPs have not yet begun to increase (Morris 1991, Morris et al. 1992). After the acute-phase protein genes have been switched on within the liver, it takes several hours before any increase in APPs can be detected in blood. This time period varies with different APPs.

Increased serum PLA $\mathrm{A}_{2}$ activity proved to be a good indicator of colic, and also distinguished between survivors and nonsurvivors (Fig. 2, Tables 3 \& 4). In human beings, serum levels of PLA $\mathrm{P}_{2}$ activity are elevated in septic shock and rheumatoid arthritis (Akira et al. 1993). The secreted form of $\mathrm{PLA}_{2}$ (group II), found in the serum, has its origin mainly in the liver. IL-6 is a major inducer of PLA 2 gene expression in hepatoma cells (Crowl et al. 1991). Therefore $\mathrm{PLA}_{2}$ may be classified as APP. Cellular $\mathrm{PLA}_{2}$ is an enzyme that plays an important role in inflammation by producing potent lipid mediators, such as leukotrienes, prostaglandins, and platelet activating factor. $\mathrm{PLA}_{2}$, attacking the intestinal mucosa, is re- garded as a central mediator of intestinal injury in inflammatory (Almer et al. 1991) and ischemic bowel disease in human beings (Otamiri \& Tagesson 1989).

The present agar diffusion method of measuring phospholipase would be too slow to justify its use in a clinical situation in which the result would be urgently needed. On the other hand, $\mathrm{PLA}_{2}$ could be replaced by SDH in the regression models without affecting the strength of the model. This reflects the multicollinearity problem in the multiple regression analysis. Two independent parameters (PLA ${ }_{2}$ and $\mathrm{SDH})$ were highly correlated as seen in the pairwise correlation matrix (Tables $3 \& 4$ ) and probably contained the same information. The strong association might indicate causation. $\mathrm{PLA}_{2}$ is a membrane-disrupting enzyme which may be responsible for the release of $\mathrm{SDH}$. SDH is known to be a cytosolic enzyme of hepatocytes and the intestinal epithelium, but is not considered as "APP" currently. If $\mathrm{PLA}_{2}$ is APP, then SDH might prove to be APP in the equine species due to the close correlation between these 2 parameters.

The use of fibrinogen as a marker of acutephase response in equine colic is intriguing. The colic horses who survived showed low fibrinogen levels at admission compared with control horses. In those colic horses who subsequently died, the variation of the fibrinogen values was high and the distribution was polarized: both high and low values were found (Fig. 1). However, the plasma fibrinogen level tended to increase in the nonsurvivors during the first $10 \mathrm{~h}$ at the clinic. Theoretically, fibrinogen should increase because it is an important APP. On the other hand, thrombotic processes consume fibrinogen, resulting in low plasma fibrinogen in colic horses (Fig. 2, Table 2). The net content of fibrinogen depends on the sequence, whether enhancement of fibrinogen synthesis or fibrinolysis oc- 
curred first. This was why we included Ddimer in the list of parameters. Imbalanced regulation of haemostasis has been shown to contribute to the pathogenetic features of equine colic (Johnston \& Crane 1986, Darien et al. 1991). The horses with hypercoagulation might show thrombotic features and the condition is often associated with increased fibrinolysis resulting in disseminated intravascular coagulation (Morris \& Beech 1983, Prasse et al. 1993). Plasma fibrinogen levels in the samples collected at admission were significantly lower in colic horses as compared with the controls. This indicates an increased consumption of fibrinogen. However, the level of fibrinogen at admission in a colic horse could not differentiate between survival or death. The wide variation of blood fibrinogen levels in nonsurviving colic horses at admission, and the increase of plasma fibrinogen towards death, indicate problems in regulation of haemostasis and APP synthesis.

Increased levels of D-dimer in plasma indicate that excessive amounts of fibrin have formed within the vascular tree but are undergoing fibrinolytic degradation. The NycoCard D-dimer test is an immunochemical test to analyze fibrinolytic problems in man. The function of this test in the equine species is not surprising. Despite the aberrant structure of equine fibrinogen, the cross-linking region of the $\mathrm{A}_{\alpha}$ chain represents the conserved portion of the fibrinogen molecule with amino acid homology and immunogenicity from one species to another (Sobel et al. 1990). This is the section contained in the D-dimer fibrin(ogen) degradation product.

The NycoCard D-dimer test has high potential for horse-site testing. After separation of plasma, the result is obtained within $2 \mathrm{~min}$. The test appeared to be practical and extremely useful for horse-site testing in emergency situations.
The importance of D-dimer in the final regression model reflects the disseminated intravascular coagulation (DIC) disorder in colic horses. The condition was more severe in nonsurvivors compared with survivors. The present analysis hints that development of DIC syndrome is the determining factor for nonsurvival. Elevated D-dimer indicates an ongoing thrombosis and fibrinolytic process. This information is valuable when designing pharmacological intervention.

When the survival (0) and death (1) of colic horses were used as the dependent variable and the other parameters on admission data as predictor variables, the binary correlations reported in Table 4 indicate that many parameters are prognostically valuable. However, when isolating the most important confounding predictor variables to be used together (Table 6), the apparent pattern changed; the most important set of variables to be used in combination on samples collected at admission were $\mathrm{D}$-dimer, chloride and heart rate. Many parameters showed collinearity with these parameters and became eliminated from the final model.

Anion gap was itself a good discriminator at admission for distinguishing between healthy and colic horses. This is in agreement with earlier reports (Gossett et al. 1987, Wirth 1986). Because of collinearity, anion gap was dropped from the logistic regression model containing heart rate, D-dimer and $\mathrm{Cl}^{-}$as predictor variables. This indicates that anion gap is contained in the information of those independent variables present in the model. Variables left out of the predictor set are not necessarily unimportant; they may simply be correlated with other variables in the predictor set. Anion gap lost its discriminating capacity totally at $10 \mathrm{~h}$ sampling (due to correction of the acid base balance by alkalinizing fluids). 
Acid-base disturbances are considered to contribute to colic-associated shock. Lactate typically accumulates in colic horses (Gossett et al. 1987, Waterman 1977). Anion gap was wide in colic horses when measured at admission. The acidotic condition was monitored carefully at the clinic and corrected by alkalinizing infusion solutions, when required. Therefore, the anion gap measured at $10 \mathrm{~h}$ was not useful at all for predicting death or survival $(\mathrm{p}=$ 0.97). This indicates that careful monitoring and correction of the acid-base status by alkalizing infusion solutions took place according to currently accepted principles. However, it is worth noting that the colic horses that later died, showed significantly higher relative increase in bicarbonate and narrowing in anion gap during the first $10 \mathrm{~h}$ compared with the survivors. The increase of bicarbonate was accompanied by a parallel increase in sodium ( $p$ $=0.07)$. This might indicate either that the rapid correction of the acidotic state by alkalizing, sodium-rich intravenous infusion solutions was detrimental to the horse, or the endogenous acid-base regulatory mechanism was disturbed in the dying horses.

The best combination of predictor sets of colic horses at admission shows that survival or nonsurvival can be predicted quite accurately by the predictor set containing D-dimer, $\mathrm{Cl}^{-}$ and heart rate (Table 6). The predictive value was surprisingly high considering other apparent sources of variation. These would certainly include the type of intestinal involvement, area of damaged intestinal wall, speed of initiating operation in respect to the onset of colic, age of the horse, time consumed in transport, transport stress, time consumed in the operation itself, surveillance of the horse including corrections in fluid-, ion-, acid-base balances and respiratory gas exchange, quality of the anaesthesiologist and the surgeon. Although the present results indicate that too rapid correction of the acid-base balance had some association with death (or more correctly euthanasia) of colic horses, the other variables were difficult to measure or were not reported, or the number of the horses was too low in each category to allow any insight to the importance of the above sources of variation.

When considering screening and computerized decision-making for equine gastrointestinal colic, there must be an understanding that the natural history of the disease and early detection can play a role in the reversal of the clinical course. Standard multivariate procedures look at the various parameters in parallel. It might be that algorithmic judgement (decision trees) would result in similar or better prediction. Multiple regression procedures require knowledge about which parameters to include in the regression model. Algorithmic procedures require knowledge of the order as well. We actually did our analysis in two steps, first it was decided whether the horse suffered from gastrointestinal colic (in this respect plasma endotoxin was quite safe parameter) and secondly the population of colic horses were analyzed for separation whether they were going to die or not.

\section{Conclusion}

The study showed that the fate of the colic horse was already determined at the time of admission to the clinic (= before surgery). Endotoxaemia was a typical feature for horses with gastrointestinal colic. The individual response to this stimulus largely determined the survival. Increasing heart rate and D-dimer together with decreasing chloride was a typical risk factor for nonsurvival. Disseminated intravascular coagulation (DIC) was probably the key element. In searching for valuable predictor parameters for decision making, it seems important to have rapid horse-site test- 
ing for the most important predictor variables. The NycoCard D-Dimer test appeared to be a practical horse-site test to detect fibrinolytic activity. An "online" method is suggested to combine the results in order to give an objective estimation of the future of the horse.

\section{Acknowledgements}

We thank Vesa Rasi, MD and Elına Vahtera, Ph.Lic. Blood Coagulation Laboratory, Red Cross Blood Transfusion Service, Helsınki for analysing the $\mathrm{f}_{1}$ brinogen content of the horse plasma standard by the fibrin-clot method and running the pilot tests on the applicability of the D-dimer test on equine plasma.

We thank Nycomed Pharma AS, Division Diagnostica POB 5012 Majorstua, N-0301 Oslo, Norway for donatıng the NycoCard D-Dimer tests for our disposal. We thank Professor Huskamp, head of the Hochmoor Animal Hospital for the colic material.

\section{References}

Akıra S, Taga T, Kıshımoto T Interleukin-6 in biology and medicine. In: D1xon FJ (ed). Advances in Immunology, 1993, 54, 1-78

Almer S, Franzen L, Olalson G, Smedh K, Strom $M$. Phospholipase $\mathrm{A}_{2}$ activity in colonic mucosa in patients with ulcerative colitis Digestion 1991, 50, 135-141.

Crowl RM, Stoller TJ, Conroy RR, Stoner CR. Induction of phospholipase $\mathrm{A}_{2}$ gene expression in human hepatoma cells by mediators of the acute phase response. J.B1ol.Chem. 1991, 266, 26472651.

Darlen BJ, Potempa J, Moore JN, Travis J. Antithrombin III actıvity in horses with colic; an analysis of 46 cases. Equine vet. J. 1991, 23, 211-214.

Gerlach U, Hiby W: Sorbitol dehydrogenase, In: Bergmeyer HU (ed.): Methods of Enzymatic Analysıs, vol 2. Academic Press N.Y. 1974, 569573

Gogstad GO, Dale S, Brosstad F, Brandnes $O$, Holtlund J, Mork E, Gartner E, Borch SM: Assay of D-dimer based on 1mmunofiltration and staining with gold collords. Clın. Chem. 1993, 39, 20702076.
Gossett KA, Cleghorn B, Martin GS. Correlation between anion gap, blood lactate concentration and survival in horse Equine vet. J 1987, 19, 2930.

Johnston IB, Crane S. Haemostatic abnormalities in horses with colic - their prognostic value. Equine vet. J. 1986, 18, 271-274.

King JN, Gerring EL $\cdot$ Detection of endotoxemia in cases of equine colic. Vet. Rec. 1988, 123, 269271.

Morrls $D D$. Endotoxemia in horses. A review of cellular and humoral mediators involved in its pathogenesis. J. vet. int. Med. 1991, 5, 167181.

Morrıs DD, Beech J Dissemınated intravascular coagulation in s1x horses. J Amer. vet. med. Assoc. 1983, 183, 1067-1072.

Morris DD, Moore JN, Crowe N, Moldawer LL: Effect of experimentally induced endotoxemia on serum interleukin-6 activity in horses. Amer. J. vet. Res. 1992, 53, 753-756.

Orsinı JA, Elser AH, Galligan DT, Donawıck WJ, Kranfeld $D S \cdot$ Prognostic index for acute abdominal crisis (colic) in horses. Amer J. vet. Res 1988, 49, 1969-1971.

Orsinı JA, Galligan DT, Reeves $M \cdot$ Determınıng a prognosis for equine abdominal crisis (colic). Equine practice 1991, 13, 9-14.

Otamirı T, Tagesson C: Role of phospholipase A2 and oxygenated free radicals in mucosal damage after small intestinal ischemia and reperfusion. Amer. J. Surg 1989, 157, 562-566.

Parry BW, Anderson GA, Gay CC: Prognosis in equine colic A comparative study of variables used to assess individual cases. Equine vet. J. 1983, 15, 211-215.

Prasse KW, Tropper MJ, Moore JN, Welles EG: Analysis of haemostasis in horses with colic. $\mathbf{J}$. Amer. vet. med. Assoc. 1993, 203, 685-693.

Puotunen-Reinert $A$. Study of variables commonly used in examination of equine colic cases to assess prognostic value. Equine vet. J. 1986, 18, 275-277.

Puotunen-Reinert A, Sandholm M: Serum phosphol1pase $\mathrm{A}_{2}$ as a prognostic variable in equine colic. Proc. 2nd Equine Colic Research Symposium, Athens, Georgia 1985, 143-148.

Reevers MJ, Curtls CR, Salman MD, Stashak TS, Reif $J F$. Validation of logistic regression models used in the assessment of prognosis and the need for surgery in equine colic. Prev. vet. Med. 1992, $13,155-172$ 
Sobel JH, Thibodeau CA, Kolks MAG, Canfield RE: Isolation and partial structural characterization of an equine fibrinogen $\mathrm{CNBr}$ fragment that exhibits immunologic cross-reactivity with $\mathrm{A}_{\alpha}$ chain cross-linking region of human fibrinogen. Biochemistry-Washington 1990, 29, 8907-8916.

Waterman A: A review of the diagnosis and treatment of fluid and electrolyte disorders in the horse. Equine vet. J. 1977, 9, 43-48.

Wel L, Floren $\mathrm{CH}$ : Hyperlipidemic response to endotoxin - a part of the host-defence mechanism. Scand. J. infect. Dis. 1993, 25, 675-682.

Wirth J: Statistical investigation on 825 cases of equine colic at the Munich Unıversity Veterinary Clinic. Dissertation (1986), Veterinary Faculty, Ludwig-Maximilian University, Germany, 200p.

\section{Sammandrag}

Plasma d-Dimer okar prognosvardet vid intestinal kollk hos hast.

Prognostiska vardet (kolıkmorbiditet, -mortalitet) av 15 klınıska och laboratorieparametrar undersoktes med hjalp av logistıska modeller. Plasma endotoxin var den basta enskilda parametern att skilja friska och kolikhastar från varandra. Okad plasma D-dimer (fibrinolys produkt) och puls tillsammans med ett sảnkt plasma kloridvarde var en riskfaktor for kolikmortalitet. Diagnostiska sensitiviteten (for prediktion an mortalitet) av denna modellen var $78 \%$ och specificiteten $77 \%$. D-dimertesten från Nycomed rekommenderas som en praktisk och prognostiskt vardefull test for hastkliniker.

(Recelved January 10, 1995; accepted March 10, 1995).

Reprints may be obtained from: M. Sandholm, Department of Clinical Sciences, College of Veterinary Medicine, Hàmeentie 57, SF-00580 Helsink1, Finland. 